\title{
A Different Form of Long-Lasting Potentiation Revealed in Tissue Plasminogen Activator Mutant Mice
}

\author{
Uwe Frey, ${ }^{1}$ Michael Müller, ${ }^{1}$ and Dietmar Kuhl² \\ ${ }^{1}$ Federal Institute for Neurobiology, 39008 Magdeburg, Germany, and ${ }^{2}$ Center for Molecular Neurobiology, University of \\ Hamburg, 20246 Hamburg, Germany
}

The establishment of hippocampal long-term potentiation (LTP) requires protein and $\mathrm{mRNA}$ synthesis, suggesting that neuronal activity resulting in LTP initiates a cascade of gene expression. The expression of the gene for the extracellular serine protease tissue plasminogen activator (t-PA) is induced during LTP. Here we analyze long-lasting LTP (L-LTP, > $4 \mathrm{hr}$ ) in CA1 hippocampal slices of mice homozygous for disrupted t-PA genes. Although mutant mice appear to exhibit long-term potentiation, we provide evidence that these mice are devoid of conventional, homosynaptic L-LTP at the Schaffer collateral-CA1 pyramidal cell synapse. Most remarkably, t-PA-deficient mice exhibit a different form of long-lasting potentiation that is characterized by an NMDA receptor-dependent modification of GABA transmission in the CAt region.

Key words: hippocampus; long-term potentiation; tissue plasminogen activator; neuronal plasticity; GABAergic transmission; gene induction
Behavioral and cellular studies of learning and memory indicate that there are phases in memory formation. Long-term memory, lasting days or even weeks in the intact animal, can be distinguished from short-term memory, lasting minutes or a few hours, with inhibitors of protein and mRNA synthesis (Flexner et al., 1963; Agranoff and Klinger, 1964; Danicls, 1971; Matthies, 1974; Grecksch and Matthies, 1980; Montarolo et al., 1986; Alkon et al., 1991). A similar time course and requirement have been described for late phases of hippocampal long-term potentiation (LTP) (Krug et al., 1984; Stanton and Sarvey, 1984; Frey et al., 1988; Otani and Abraham, 1989; Frey et al., 1993a,b; Nguyen et al., 1994; Frey et al., 1995), a widely studied process thought to underlie explicit forms of memory (Squire et al., 1993). The requirement of protein and mRNA synthesis during LTP might reflect alterations in gene transcription, but little is known about the specific genes induced and their role, if any, in LTP. The expression of the gene for the extracellular serine protease tissue plasminogen activator (t-PA) has been shown to be induced during LTP and might contribute to structural changes that can be observed during activity-dependent plasticity (Qian et al., 1993). Mice genetically engineered to be deficient for t-PA develop normally, are fertile, and have a normal life span (Carmeliet et al., 1994). Moreover, a histochemical analysis, which we performed on the brains of t-PA-deficient mice, did not reveal any gross anatomical abnormalitics in hippocampus or other rcgions of the brain.

Here we examine how the absence of t-PA gene expression affects synaptic transmission and the establishment and mainte-

Received Oct. 10. 1995; revised Dec. 26, 1995; accepted Jan, 4, 1996.

This work was supported by the German Bundesministerium für Bildung, Wissenschaft, Forschung, und Technologie (FKZ: 0310258A to U.F.) and the Hans and Lieselotte Ritz Stiftung (D.K.). We are grateful to Peter Carmeliet, who made the t-PA-deficient mice available to our investigation. We thank Roger A. Nicoll and Hansjürgen Matthies for critical comments on this manuscript, and Diana Koch, Sabine Mücke, and Kathrin Schumacher for skillful technical assistance.

Correspondence should be addressed to Uwe Frey, Federal Institute for Neurobiology, Gene Regulation and Plasticity, Brenneckestrasse 6, P.O. Box 1860, 39008 Magdeburg, Germany.

Copyright 1996 Socicty for Neuroscience $0270-6474 / 96 / 162057-07 \$ 05.00 / 0$ nance of long-lasting LTP (L-LTP) in the hippocampal CAl region. We report that stimulation parameters used for the induction of LTP in wild-type animals elicit a distinct form of longlasting potentiation in mice deficient for t-PA. Although the observed potentiation appears to be phenotypically similar to conventional, homosynaptic LTP, we find that long-lasting potentiation in t-PA-deficient mice is mediated by an NMDA receptordependent modification of GABA transmission.

\section{MATERIALS AND METHODS}

Hippocampal slices in vitro were prepared from 81 adult mice. t-PA. deficient and wild-type mice (Carmeliet et al., 1994) were obtained from Dr. P. Carmeliet, Catholic University of Leuven, Leuven, Belgium. Experiments were performed under blind conditions, i.e. all animals used were received mixed and coded, and their genotype was determined by Dr. Carmeliet. Electrophysiological recordings were described previously (Frey et al., 1988) with the following exception. The mice were briefly anesthetized with chloroform until they were motionless $(<15 \mathrm{sec})$. Then the animals were killed rapidly by decapitation. The slices were incubated in an interface chamber at $32^{\circ} \mathrm{C}$ and at a flow rate of artificial CSF of 1 $\mathrm{ml} / \mathrm{min}$. Monopolar, lacquer-coated, stainless stecl electrodes (A-M Systems, Everett, WA) were positioned in the stratum radiatum of the CAl region for stimulation. For recording, two electrodes were placed in the CAl dendritic and cell body layer, respectively. After a $4-5 \mathrm{hr}$ preincubation period, the stimulation strength was determined for further testing by eliciting a pop-spike of $25 \%$ of its maximal amplitude. The baseline was recorded for at least $60 \mathrm{~min}$ before LTP induction. Four $0.2 \mathrm{~Hz}$ biphasic, constant-current pulses $(0.1 \mathrm{mscc}$ per polarity) were used for testing $1,3,5,11,15,21,25$, and 30 min posttetanus, and thereafter once every $15 \mathrm{~min}$. A prolonged potentiation was induced in one input using three stimulus trains of 100 pulses $(100 \mathrm{~Hz}$, duration $0.2 \mathrm{msec}$ per polarity) with $10 \mathrm{~min}$ intertrain intervals. This particular schedule of tetanization was used to produce a robust and very stable long-term maintenance of potentiation in vitro for $>8 \mathrm{hr}$ (Reymann et al., 1985; Frey et al., 1988).

For paired-pulse stimulation, the same stimulus intensity was used as for testing. Interpulse intervals of $25,50,75$, and 100 misec were investigated. Input-output curves were obtained by alternating stimulation with intensities of $0,20,40,60,80$, and $100 \%$ of the stimulus intensity required for eliciting a maximal pop-spike in each slice. 'The pop-spike $(\mathrm{mV})$ was evaluated by taking the voltage difference between onset and peak. The slope function $(\mathrm{mV} / \mathrm{msec})$ of the field EPSP was calculated from eight successive points of the steepest $400 \mu \mathrm{sec}$ segment.

Experiments determining the effect of $\mathrm{GABA}_{\Lambda}$ receptor blockade on 
A

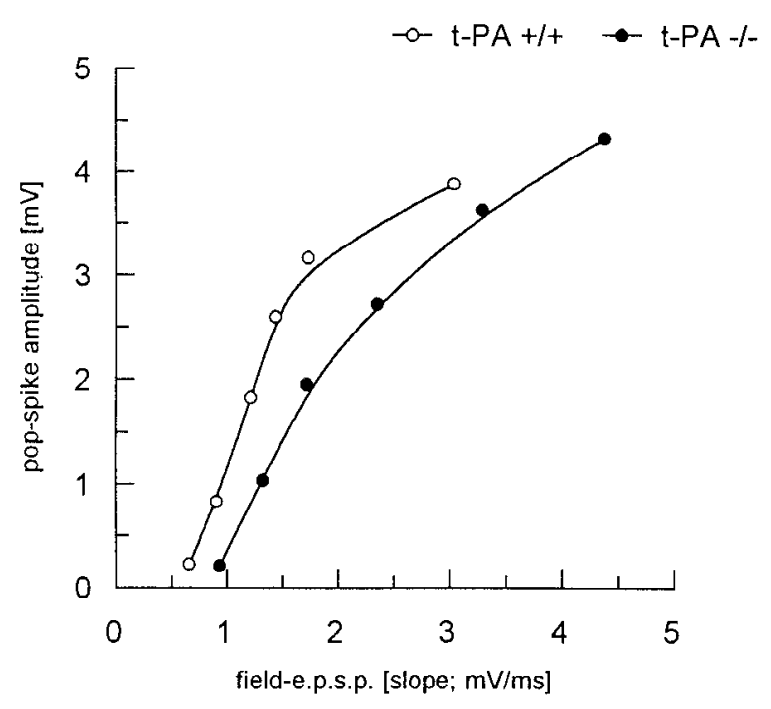

C

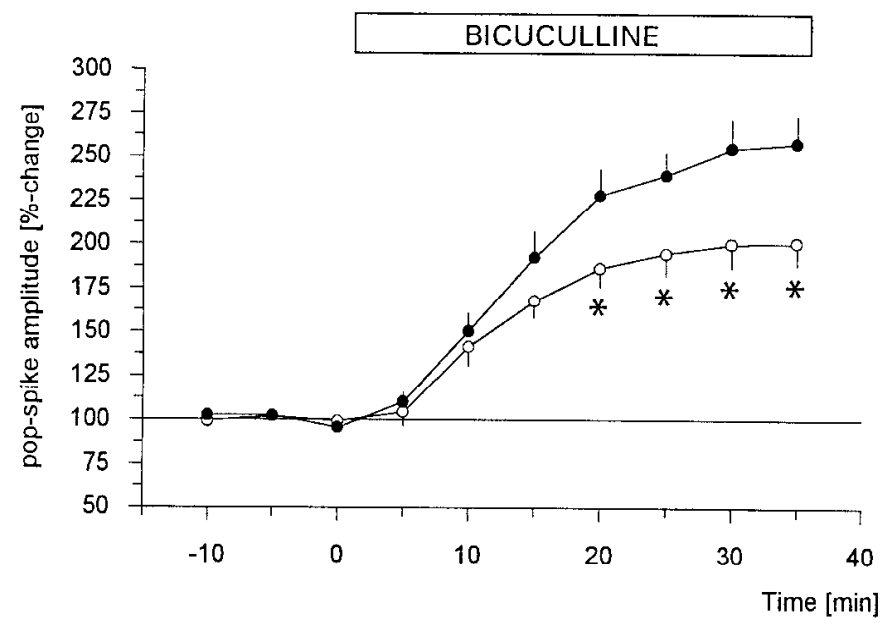

B
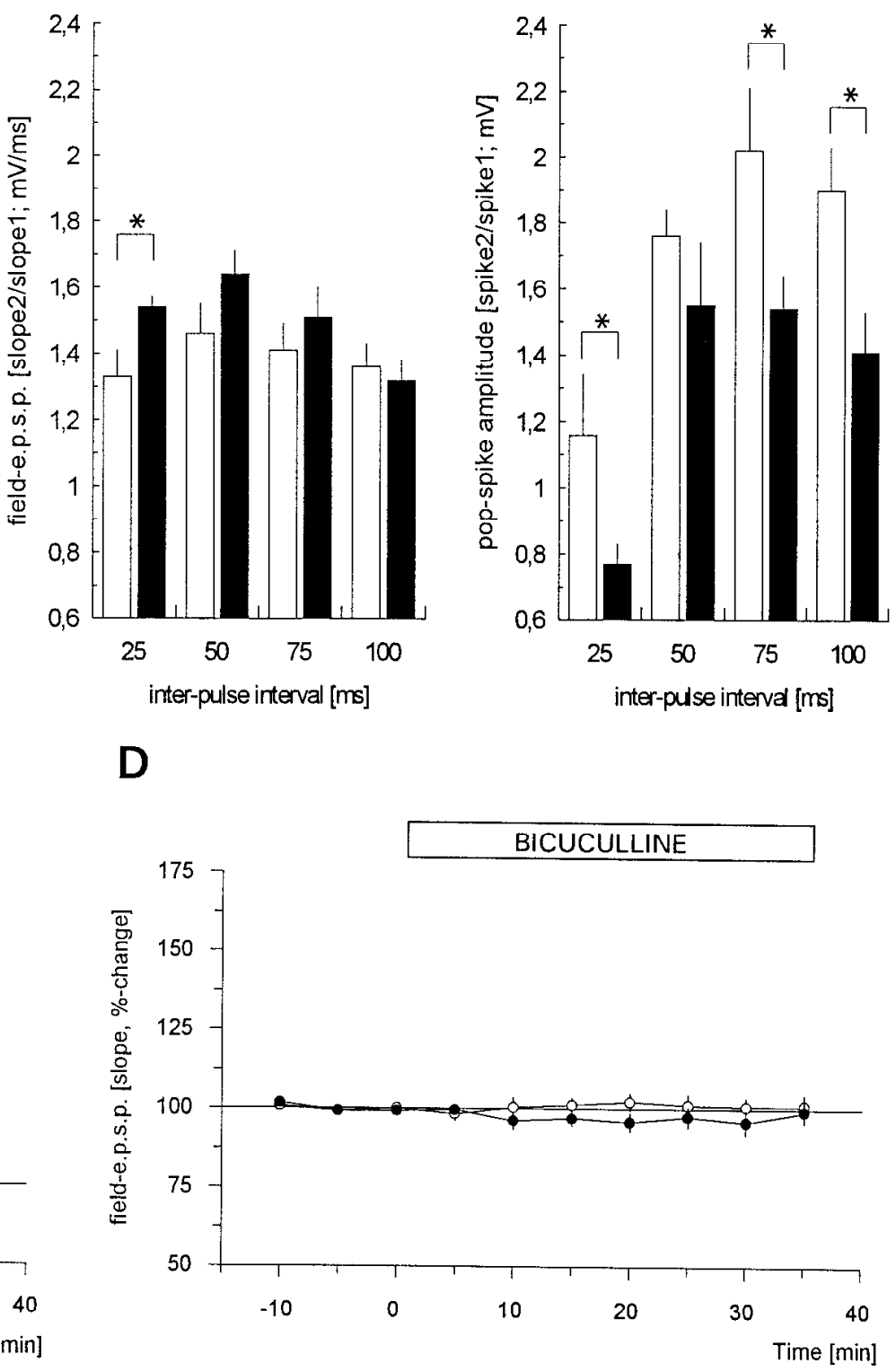

Figure 1. Differences in synaptic transmission of $\mathrm{t}-\mathrm{PA}^{+/+}$and $\mathrm{t}-\mathrm{PA}^{-/-}$mice. $A$, EPSP-spike (E-S) relationship of wild-type (open circles, $\left.n=6\right)$ and mutant animals (filled circles, $n=6$ ). t-PA-deficient mice require larger EPSPs than wild-type mice to generate a spike of similar amplitudes. $B$, Paired-pulse behavior of field LPSP (left) and the pop-spike amplitudes (right) of wild-type (open burs, $n=7$ ) and mutant mice (filled bars, $n=7$ ) are shown as the quotient of the slope of the EPSP or the spike amplitude of the second evoked potential and the first potential (potential2/potential1). Analyzing the EPSP, a slight enhanced paired-pulse facilitation in the mutant animals was observed only at an interpulse interval of 25 msec compared with wild-type mice. In contrast to the relatively small changes in the EPSP, a significantly larger depression of the second potential was observed in mutant animals at interpulse intervals of 25,75 , and $100 \mathrm{msec}$, indicating stronger inhibition in mutant mice. $C$ and $D$ show the time course of pop-spike amplitudes $(C)$ and the field EPSP (slope, percentage change; $D$ ) after application of $10 \mu \mathrm{M}$ bicuculline methchloride. Compared with wild-type mice (open circles, $n=10$ ), mutant animals (filled circles, $n=8$ ) reveal a larger enhancement of the spike, suggesting an increased GABAergic transmission in mutant animals during low-frequency stimulation. $D$, The field EPSP was unaffected by bicuculline in both animal groups. Asterisks in $B$ and $C$ indicate statistically significant differences using the two-tailed Mann-Whitney $U$ test $(p<0.05$; each point shown is the mean \pm SFM).

synaptic transmission were conducted as follows. After the preincubation period of $5 \mathrm{hr}$, the stimulation intensity was determined as described. A baseline was recorded for $30 \mathrm{~min}$ before $10 \mu \mathrm{M}$ bicuculline methchloride (dissolved in incubation medium by sonication; all substances were obtained from Research Biochemicals International, Cologne, Germany) was applied continuously. The time course of the effect of bicuculline on the potentials was followed for $35 \mathrm{~min}$. In experiments investigating the effect of $\mathrm{GABA}_{\mathrm{A}}$ receptor blockade after the establishment of LTP, the stimulus intensity was reduced after $1 \mathrm{hr}$ of LTP in order to elicit potentials of an amplitude similar to those recorded before tetanization, and a new baseline was recorded for $10 \mathrm{~min}$. Then bicuculline was applied as in the experiments without LTP induction, and potentials were followed for 35 minir.

In experiments examining the effect of picrotoxin (PTX) or D(-)-2amino-5-phosphonopentanoic acid (AP-5) on LTP, $10 \mu \mathrm{M}$ PTX or $50 \mu \mathrm{M}$ AP- 5 were applied $1 \mathrm{hr}$ before the start of recording and maintained in the bath for the entire experimental session. When both drugs were used, AP-5 was applied 5 min before PTX.

In experiments using bicuculline or PTX, the CA3 region of the hippocampal slice was removed by a microsurgical cut. 

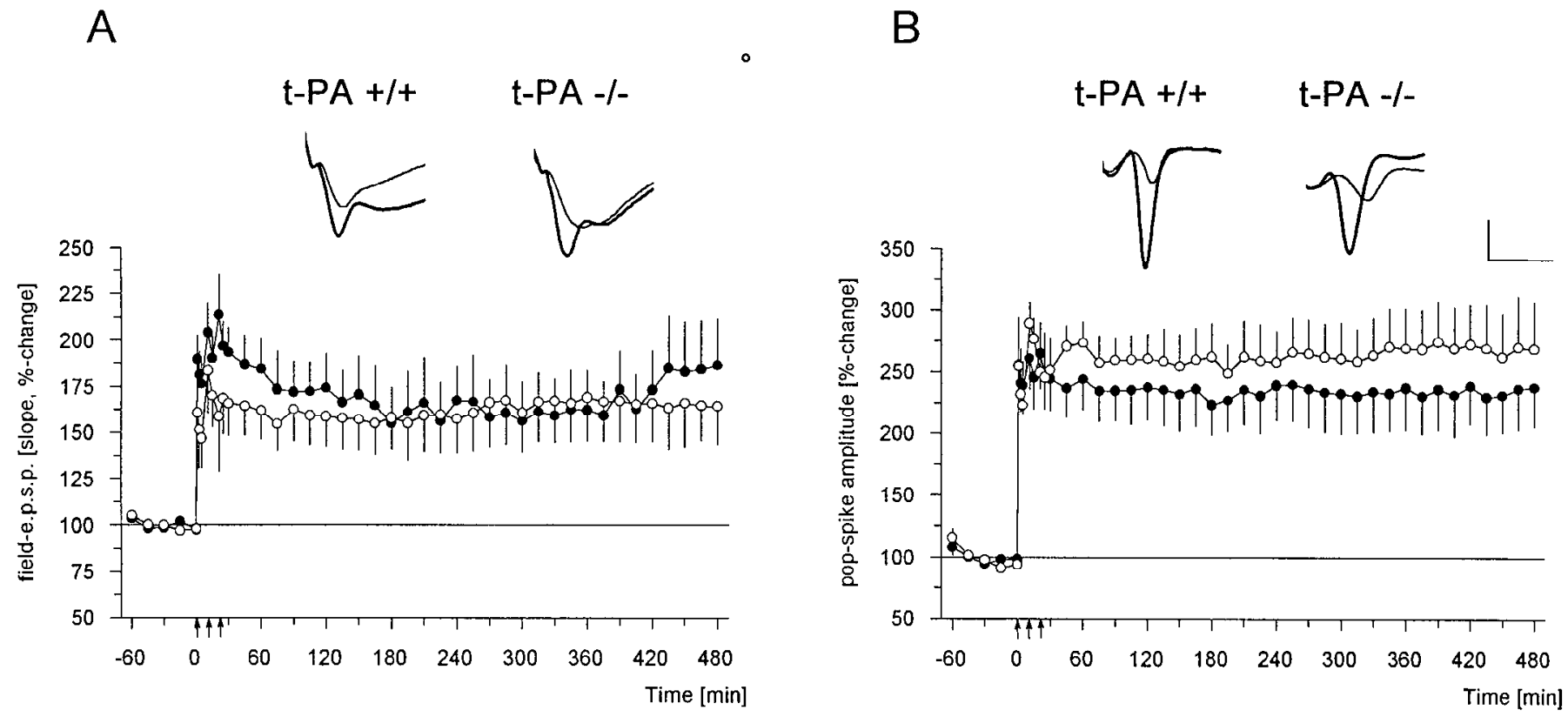

Figure 2. LTP and long-lasting potentiation in hippocampal slices of t-PA ${ }^{1 / t}$ and $\mathrm{t}-\mathrm{PA}^{-1}$ mice. $A$, Time course of the percentage change of the slope of field EPSPs and $(B)$ of the population spikc amplitude (pop-spikc) in t-PA-deficient (filled circles, $n=8)$ and wild-type mice $($ open circles, $n=8$ ). Threefold tetanization resulted in stable potentiation in both animal groups for $8 \mathrm{hr}$ (each point shown is the mean of averaged potentials \pm SEM). Insets show typical examples of superimposed traces of EPSPs $(A)$ and pop-spikes $(B)$ before and $8 \mathrm{hr}$ after tetanization for each animal group. Arrows indicate the time point of threefold tetanization. Calibration bars: $1 \mathrm{mV} ; 5 \mathrm{msec}$.

\section{RESULTS}

In a first series of experiments, we examined properties of synaptic transmission in wild-type and mutant animals. Figure $1 A$ shows the EPSP-spike (E-S) relationship using a series of stratum radiatum test pulses of increasing intensity (Andersen et al., 1980; Chavez-Noriega et al., 1989). t-PA-deficient animals (Fig. 1 $A$, filled circles) require a larger EPSP then wild-type mice to generate a similar population spike compared with wild-type mice (Fig. $1 A$, open circles). This finding was further evidenced by the observation that an increased stimulus intensity was needed to elicit a similar pop-spike amplitude in the mutant animals (e.g., to obtain a pop-spike with an amplitude of $50 \%$ of the maximal amplitude, $55.17 \pm 4.25 \mu \mathrm{A}$ (mean $\pm \mathrm{SEM}, n=8$ ) were used in wild-type mice and $66.10 \pm 5.58 \mu \mathrm{A}(n=8)$ were used in mutant mice). The reduced excitability of the mutant mice could be attributable to an increased feedforward inhibition in the dendritic field and the pyramidal cell body layer and might be conferred by GABAergic transmission (Kairiss et al., 1987). As a second index of synaptic transmission, we tested paired-pulse behavior in both animal groups (Fig. $1 B$ ). Paired-pulse facilitation of the field EPSP of mutant animals was slightly larger than EPSP facilitation of wild-type mice at an interpulse interval of $25 \mathrm{msec}$ (Fig. I $B$, left), which might suggest an increased feedforward inhibition (Lambert et al., 1991) in the dendritic field of mutant animals. Paircd-pulse bchavior of the pop-spikc in mutant mice (Fig. $1 B$, right, black boxes) was characterized by a significantly reduced paired-pulse facilitation of the second pop-spike at interpulse intervals of 25,75 , and $100 \mathrm{msec}$, suggesting an increased feedback inhibition (Maru et al., 1989; Lambert et al., 1991) in the mutant mice. We therefore examined GABAergic transmission. Figure $1, C$ and $D$, shows the influence of the $\mathrm{GABA}_{\mathrm{A}}$ receptor blucker bicuculline on normal synaptic transmission in both animal groups. Whereas bicuculline had no effect on the field EPSP in the two groups, we found that the pop-spike showed a significantly increased facilitation in the mutant animals. These results support the possibility of an altered GABAergic inhibition in the t-PA mutant mice.

In a second series of experiments, we investigated whether induction or maintenance of LTP is affected in t-PA-deficient mice. A robust and enduring form of LTP in the CA1 region of hippocampal slices in vitro (L-LTP, lasting for at least $8 \mathrm{hr}$ ) was generated using a conditioning protocol reported carlicr (Frey et al., 1988; Frey et al., 1993a). Electrically induced potentiation in $\mathrm{t}$-PA-deficient mice was phenotypically similar to LTP observed in wild-type mice and was maintained in vitro for at least $8 \mathrm{hr}$ (Fig. $2 A, B)$. We examined in parallel the E-S relationship in the two animal groups during LTP (Fig. 3A,B). The E-S curve of wild-type mice showed a characteristic left shift 50 min after induction of LTP (Fig. 3A). This left shift is indicative of an additional popspike increase and is interpreted as enhanced excitability of the pyramidal cells after LTP induction (Andersen et al., 1980). In contrast, the $\mathrm{E}-\mathrm{S}$ relationship of the mutants did not show any left shift (Fig. 3B). Moreover, compared with wild-type mice, the slope of the E-S curve of the mutant mice was decreased before and after induction of long-lasting potentiation, consistent with the hypothesis that GABAergic inhibition is altered (Kairiss et al., 1987; Chavez-Noriega et al., 1989) in mutant animals. To further test this hypothesis, wc adjusted the stimulus intensities during the maintenance phase of LTP ( $1 \mathrm{hr}$ after LTP induction) to elicit potentials of an amplitude similar to those recorded before tetanization. Bicuculline methchloride $(10 \mu \mathrm{M})$ was applied, and potentials were recorded for $35 \mathrm{~min}$. In contrast to measurements performed before induction of LTP (Fig. 1C), no additional facilitation of the pop-spike amplitude after $\mathrm{GABA}_{\wedge}$ receptor blockade was observed in $\mathrm{t}$-PA-deficient mice after the induction of LTP (Fig. 3C) compared with wild-type animals. This result 
A

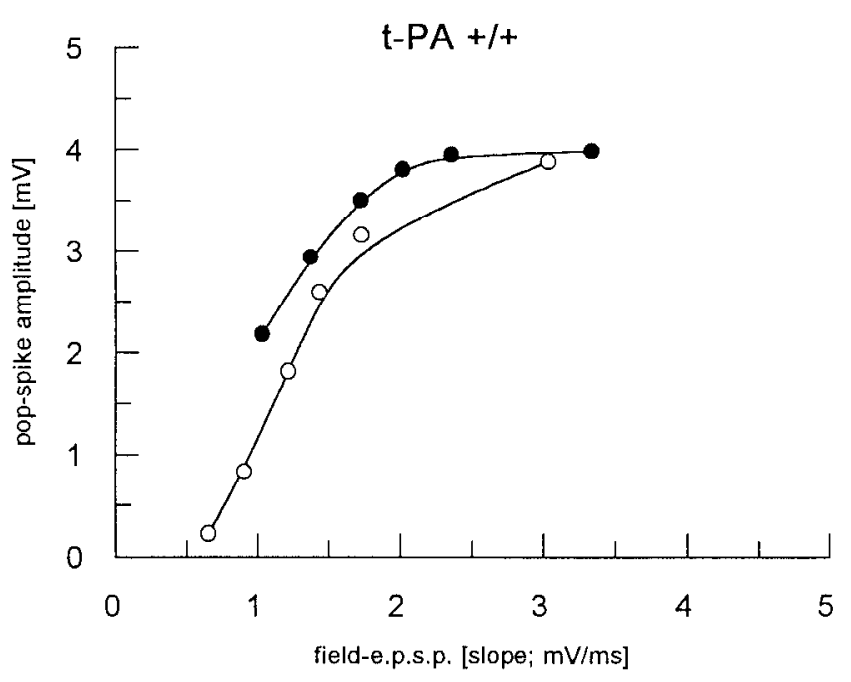

C

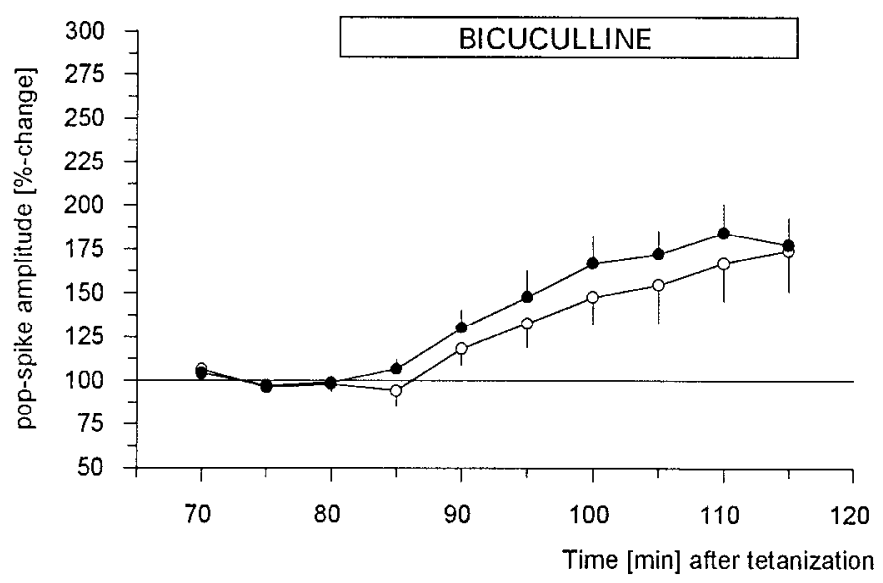

B

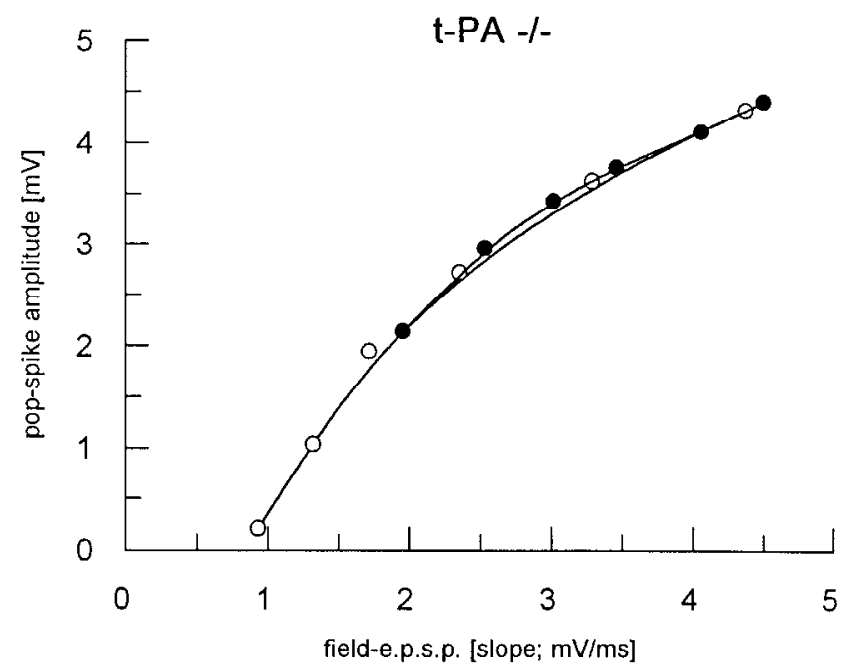

D

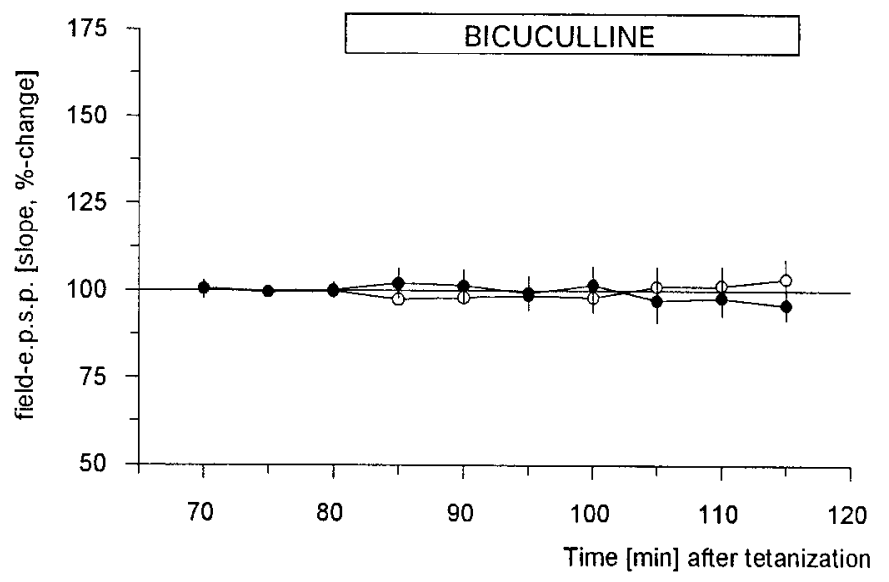

Figure 3. Comparison of properties of synaptic transmission of t-PA ${ }^{+1+}$ and t-PA ${ }^{-1-}$ animals after induction of LTP. E-S relationship of wild-type $(n$ =6) $(A)$ and mutant mice $(B)(n=6)$ before (open circles) and 50 min after tetanization (filled circles). In contrast to wild-type mice, mutants do not show the characteristic left shift of the E-S curve after tetanization. Moreover, mutants require a larger EPSP to evoke a similar pop-spike. $C, D$, Effect of $10 \mu \mathrm{M}$ bicuculline methchloride on the spike $(C)$ and EPSP $(D) 80 \mathrm{~min}$ after LTP induction. One hour after tetanization, the stimulus intensity was adjusted to evoke potentials with an amplitude similar to those before tetanization. This adjustment of the stimulus intensitics allows a comparison of potentials before LTP and bicuculline treatment (Fig. 1C,D) and potentials obtained after induction of LTP and application of bicuculline. A baseline was recorded with the newly adjusted stimulus intensities for $10 \mathrm{~min}$. Slices were then treated with bicuculline, i.e., 80 min after induction of LTP, and the time course of potentials was recorded for an additional $35 \mathrm{~min}$. Whereas with control stimulation and bicuculline before tetanization mutant mice showed significantly enhanced potentials compared with wild-type mice (pop-spike, see Fig. 1C), 80 min after induction of LTP, the pop-spike amplitude (C) of t-PA-deficient animals (filled circles, $n=7$ ) was not different from potentials of wild-type animals (open circles, $n=9$ ). This result indicates a reduction of GABAergic transmission in t-PA-deficient mice 80 min after LTP generation.

indicates an LTP-specific reduction of GABAergic transmission in $t$-PA-deficient mice. The reduced facilitation of the pop-spike with bicuculline and LTP induction in both animal groups (Fig. $3 C$ ) is reminiscent of the disinhibition observed with LTP in hippocampal CA1 neurons (Stelzer et al., 1994).

In the following experiments, we examined the role of GABAergic inhibition for the induction and maintenance of potentiation. LTP was induced in the presence of the $\mathrm{GABA}_{\mathrm{A}}$ receptor inhibitor PTX $(10 \mu \mathrm{M})$, and potentials were tested in the presence of PTX using a stimulation intensity that elicited
$25 \%$ of the maximal pop-spike amplitude. Slices of wild-type animals treated in this way showed an increase in the slope of the field EPSP as well as the pop-spike amplitude, evidencing the establishment and maintenance of LTP (Fig. $4 A, B$, open circles). Tetanization of wild-type slices in PTX led to stable LTP with enhanced potentials somewhat smaller compared with those observed in nontreated LTP slices of wild-type controls (see Discussion). In our studies, we also noted that inhibition of GABA transmission and tetanization elicited a marked increase in the number of multispikes, a further index 
A

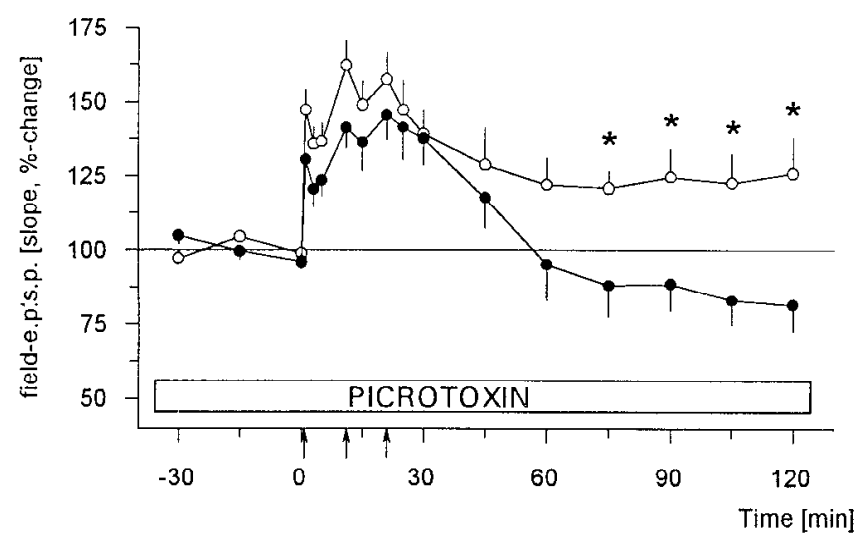

C

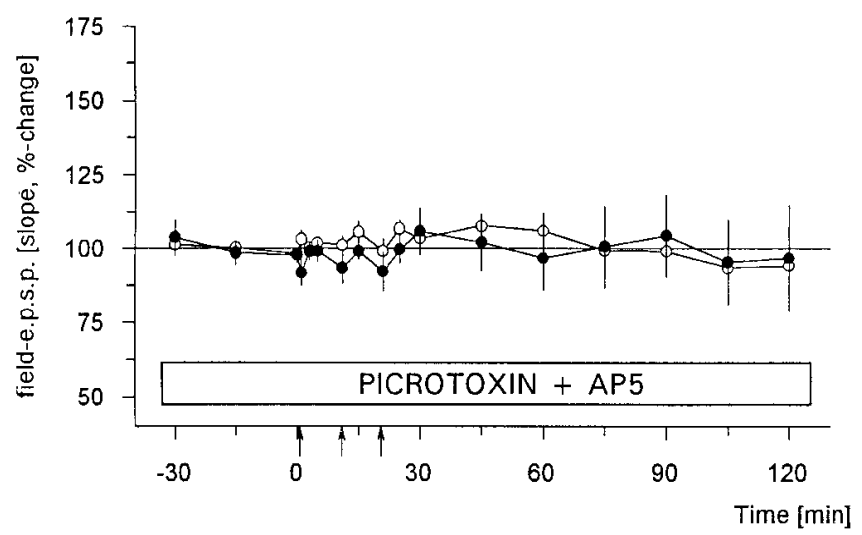

B

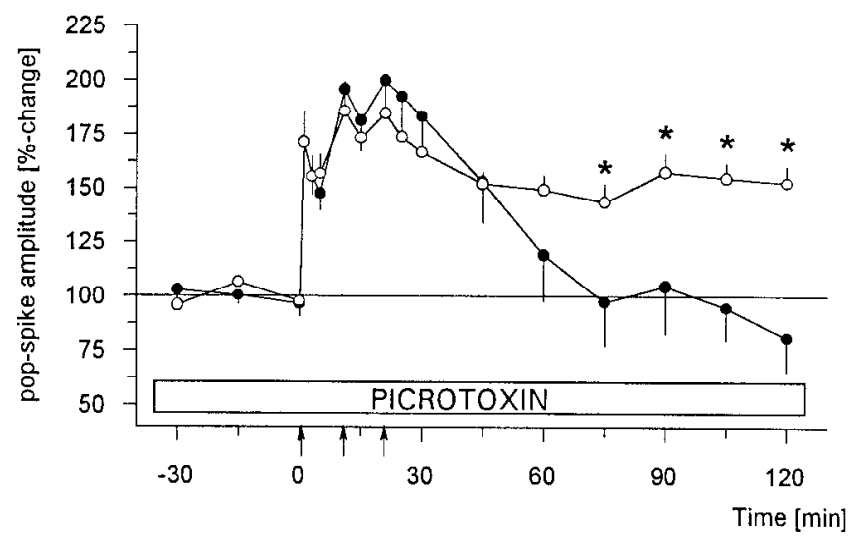

D

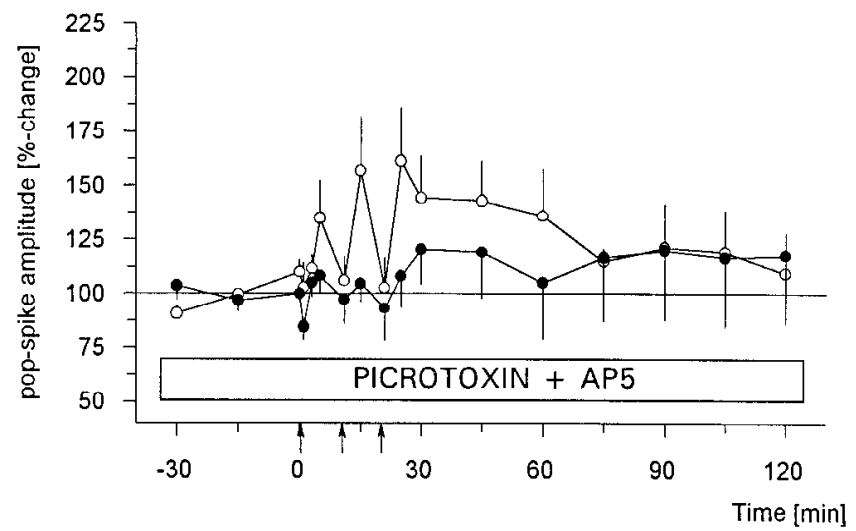

Figure 4. Time course of long-lasting potentiation in t-PA ${ }^{+/+}$and $\mathrm{t}-\mathrm{PA}{ }^{-1-}$ mice in the presence of PTX or AP-5. $A, B$, Time course of potentiation of the field EPSP and the pop-spike in wild-type (open circles, $n=10$ ) and t-PA-deficient mice (filled circles, $n=9$ ) after application of PTX. In the latter, only a short-term potentiation could be evoked. Asterisks indicate the statistically significant difference between the mutant and wild-type mice after application of PTX (Mann-Whitney $U$ test, $p<0.05$ ). Arrows indicate the time point of threefold tetanization. $C, D$, Time course of potentiation of the field EPSP and of the pop-spike in t-PA ${ }^{+/+}$(open circles, $n=7$ ) and t-PA ${ }^{-1-}$ mice (filled circles, $n=6$ ) after application of AP-5. Application of AP-5 alone prevented a lung-lasting potentiation in the two aninial groups.

for the establishment of LTP in slices of wild-type mice. In strong contrast, in the presence of PTX, slices of mutant animals did not show a maintained long-lasting enhancement of potentials. Mutant mice were completely devoid of late phases of potentiation and showed only a short-lasting potentiation declining to baseline values within $60 \mathrm{~min}$ after tetanization (Fig. $4 A, B$, filled circles).

Hippocampal CA1-LTP depends on the activation of NMDA receptors. We investigated whether the long-lasting potentiation in t-PA-deficient mice has a similar requirement. Application of the NMDA receptor blocker D-AP-5 $(50 \mu \mathrm{M})$ during tetanization abolished all forms of longer-lasting potentiation in wild-type as well as mutant mice (Fig. 4C,D), demonstrating that the two forms of long-lasting potentiation depend on the activation of NMDA receptors.

\section{DISCUSSION}

t-PA is widely expressed in the developing and the adult brain (Qian et al., 1993; Carroll et al., 1994). Thus, the loss of t-PA could conceivably lead to neuroanatomical deficits. Light microscopical examination of the neocortex, cerebellum, and hippocampus using Nissl- and immunohistochemical staining of microtubule-associated protein 2, synaptophysin, calbindin$\mathrm{D}_{28 \mathrm{~K}}$, calretinin, and parvalbumin did not reveal a rearrangement or a difference in the number of excitatory and inhibilory cell populations, or any other gross anatomical changes (data not shown). However, our analysis cannot exclude more subtle structural abnormalities in mutant mice. t-PA might participate in structural rearrangements associated with development and/or synaptic plasticity in the adult brain (Qian et al., 1993; Carroll et al., 1994). t-PA might enhance glutamate-evoked intracellular calcium increase through modulation of the NMDA receptor, which could contribute to the initiation of processes required for L-LTP (Inoue et al., 1994). We cannot distinguish between these possibilities, but we clearly demonstrate an essential role of L-PA for the maintenance of LTP at the Schaffer collateral-CA1 pyramidal cell synapse. 
Our results indicate that the absence of t-PA gene expression affects synaptic transmission and the establishment and maintenance of L-LTP. During control stimulation, t-PA-deficient animals are characterized by a stronger GABAergic transmission in the hippocampal CA1 region. This finding might explain the recent observation (Tsirka et al., 1995) that t-PA-deficient animals are less susceptible to pharmacologically induced seizures compared with wild-type mice.

If the augmentation of the $\mathrm{GABA}_{\mathrm{A}}$ inhibition in mutant mice is indicative of greater activities across the full range of $\mathrm{GABA}_{\mathrm{A}}$ receptor functions, one might expect a similar augmentation during high-frequency stimulation (Alger and Nicoll, 1982a,b; Lambert et al., 1991; Staley et al., 1995). Such augmentation of the depolarizing effects of $\mathrm{GABA}_{\mathrm{A}}$ receptor activation in mutant micc might lead to incrcascd activation of NMDA receptor-dependent processes and might account for the long-lasting potentiation in the field EPSP as well as the pop-spike. Additionally, after high-frequency stimulation, GABAergic transmission is greatly reduced in mutant animals by NMDA receptor-dependent mechanisms. The reduced GABAergic transmission in t-PA-deficient mice contributes significantly to a potentiation of the pop-spike, which shows a similar time course as conventional L-LTP observed in wildtype mice. Blockade of the inhibitory system completely inhibited the maintenance of LTP in t-PA-deficient mice, whereas wild-type animals expressed robust L-LTP, although at slightly decreased levels. This slight reduction might indicate that, perhaps on a limited scale, GABA transmission is contributing to LTP also in wild-type animals. Our observation that $\mathrm{GABA}_{\mathrm{A}}$ receptor blockade results in reduced levels of LTP in wild-type animals is in contrast to an earlier report showing a larger potentiation after tetanization of the perforant path under these conditions (Wigström and Gustafsson, 1983). However, these results were obtained in the dentate gyrus and can be reconciled with our findings by a different GABAergic modulation in the dentate gyrus and the CAl region of the hippocampus, or simply by the different stimulation protocols used. A different study in our laboratory on hippocanpal slices of rat also did not show a facilitation of potentiation during the first $2 \mathrm{hr}$ of LTP in the CA1 region when GABAergic transmission was blocked (Schollmeier et al., 1995).

The obtained results show that the increase in synaptic efficacy in t-PA mutants is distinct from conventional L-LTP and represents a novel form of long-lasting potentiation. Glutamatergic transmission alone is insufficient in generating processes resulting in LTP in the t-PA mutant mice and requires an additional, GABA-dependent mechanism.

Taken together, t-PA-deficient mice completely lack conventional, homosynaptic L-LTP. Heterosynaptic long-lasting potentiation, however, does not require the expression of t-PA and is mediated in addition to conventional LTP by an NMDA receptor-dependent modification of GABAergic transmission. This form of potentiation provides t-PA-deficient mice with an output of CA1 neurons identical to that seen in wild-type mice during conventional L-LTP and, functionally, might fully compensate for L-LTP. Compensation of conventional I.TP hy a GABA-dependent potentiation could explain why spatial memory formation is unaffected in mutant mice (Lipp et al., 1993). This novel cellular plastic process might occur only in t-PAdeficient mice or, alternatively, it may appear in wild-type mice concomitant with, and until now indiscernible from, conventional, homosynaptic LTP. Our observation that PTX treat- ment and tetanization results in reduced enhanced potentials in wild-type animals would support this notion. In this case, a neuronal population would use at least two distinct mechanisms subserving a prolonged increase in synaptic efficacy. t-PA-deficient mice might provide an ideal model and tool to further characterize the physiological consequences of a GABAergic contribution to LTP.

\section{REFERENCES}

Agranoff BW, Klinger PD (1964) Puromycin effect on memory formation in the goldfish. Science 146:952-953.

Alger BE, Nicoll RA (1982a) Feed-forward dendritic inhibition in rat hippocampal pyramidal cells studied in vitro. J Physiol (Lond) 328:105-123.

Alge: BE, Nicoll RA (1982b) Pharmacological evidence for two kinds of GABA receptor on rat hippocampal pyramidal cells studied in vitro. J Physiol (Lond) 328:125-141.

Alkon DL, Amaral DG, Bear MF, Black J, Carew TJ, Colıen NJ, Disterhoft JF, Eichenbaum H, Golski S, Gorman LK, Lynch G, McNaughton BL, Mishkin M, Moyer JRJ, Olds JL, Olton DS, Otto T, Squirc LR, Staubli U, Thompson LT, Wible C (I94) Learning and memory. Brain Res Rev 16:193-220.

Andersen P, Sundberg SH, Sveen O, Swann JW, Wigström H (1980) Possible mechanisms for long-lasting potentiation of synaptic transmission in hippocampal slices from guinea pigs. J Physiol (Lond) 302:463-482.

Carmeliet P, Schoonjans L, Kieckens L, Ream B, Degen J, Bronson R, De Vos R, Van den Oord JJ, Collen D, Mulligan RC (1994) Physiological consequenes of loss of plasminogen activator gene function in mice. Nature 368:419-424.

Carroll PM, Tsirka SE, Richards WG, Frohman MA, Strickland S (1994) The mouse tissue plasminogen activator gene 5 ' flanking region directs appropriate expression in development and a seizure-enhanced response in the CNS. Development 120:3173-3183.

Chavez-Noriega LE, Bliss TV, Halliwell JV (1989) The EPSP-spike (E-S) component of long-term potentiation in the rat hippocampal slice is modulated by GABAergic but not cholinergic mechanisms. Neurosci Lett 104:58-64.

Daniels D (1971) Effects of actinomycin D on memory and brain RNA synthesis in an appetitive learning task. Nature 231:395-397.

Flexner JB, Flexner LB, Stellar E (1963) Memory in mice is affected by intracerebral puromycin. Science 141:51-59.

Frey U, Krug M, Reymann KG, Matthies H (1988) Anisomycin, an inhibitor of protein synthesis, blocks late phases of LTP phenomena in the hippocampal CA1 region in vitro. Brain Res 452:57-65.

Frey U, Huang Y-Y, Kandel ER (1993a) Effects of cAMP simulate a late stage of LTP in hippocampal CA1 neurons. Science 260:1661-1664.

Frey U, Seidenbecher T, Krug M (1993b) The action of the RNAsynthesis inhibitor actinomycin D on a late stage of LTP in hippocampal neurons in vivo and in vitro. Soc Neurosci Abstr 19:912.

Frey U, Frey S, Schollmeier F, Krug M (1995) Influence of actinomycin D, a RNA-synthesis inhibitor, on long-term potentiation in rat hippocampal neurons in vivo and in vitro. J Physiol (Lond) 490:703-711.

Grecksch G, Matthies H (1980) Two sensitive periods for the amnesic effect of anisomycin. Pharmacol Biochem Behav 12:663-665.

Inoue K, Koizumi S, Nakajima K, Hamanoue M, Kohsaka S (1994) Modulatory effect of plasminogen on NMDA-induced increase in intracellular frec calcium concentration in rat cultured hippocampal neurons. Neurosci Lett 179:87-90.

Kairiss EW, Abraham WC, Bilkey DK, Goddard GV (1987) Field potential evidence for long-term potentiation of feed-forward inhibition in the rat dentate gyrus. Brain Res 401:87-94.

Krug M, Lössner B, Ott T (1984) Anisomycin blocks the late phase of long-term potentiation in the dentate gyrus of freely moving rats. Brain Res Bull 13:39-42.

Lambert NA, Borroni AM, Grover LM, Teyler TJ (1991) Hyperpolarizing and depolarizing $\mathrm{GABA}_{\mathrm{A}}$ receptor-mediated dendritic inhibition in area CA1 of the rat hippocampus. J Neurophysiol 66:1538-1548.

Lipp H-P, Wolfer DP, Bozizevic M, Carmeliet P, Collen D, Mulligan RM (1993) Swimming navigation learning in mice deficient for tissue plasminogen activator: impaired acquisition but intact spatial memory. Soc Neurosci Abstr 19:799. 
Maru E, Ashida H, Tatsuno J (1989) Long-lasting reduction of dentate paired-pulse depression following LTP-inducing tetanic stimulations of perforant path. Brain Res 478:112-120.

Matthies H (1974) The biochemical basis of learning and memory. Life Sci 15:2017-2031.

Montarolo PG, Goelet P, Castellucci VF, Morgan J, Kandel ER, Schacher $S$ (1986) A critical period for macromolecular synthesis in long-term heterosynaptic facilitation in Aplysia. Science 234:1249-1254.

Nguyen PV, Abel T, Kandel ER (1994) Requirement of a critical period of transcription for induction of a late phase of LTP. Science 265:1104-1107.

Otani S, Abraham WC (1989) Inhibition of protein synthesis in the dentate gyrus, but not the entorhinal cortex, blocks maintenance of long-term potentiation in rats. Neurosci Lett 106:175-180.

Qian Z, Gilbert ME, Colicos MA, Kandel ER, Kuhl D (1993) Tissueplasminogen activator is induced as an immediate-early gene during seizure, kindling and long-term potentiation. Nature 361:453-457.

Reymann KG, Malisch R, Schulzeck K, Brödemann R, Ott T, Matthies H (1985) The duration of long-term potentiation in the CA1 region of the hippocampal slice preparation. Brain Res Bull 15:249-255.
Schollmeier K, Schollmeier F, Frey U (1995) Does the late maintenance of CA1-LTP depend on GABA-ergic inhibition? Soc Neurosci Abstr 21:1103.

Squire LR, Knowlton B, Musen G (1993) The structure and organization of memory. Annu Rev Psychol 44:453-495.

Stalcy KJ, Soldo BL, Proctor WR (1995) Ionic mechanisms of neuronal

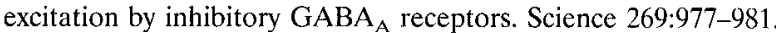

Stanton PK, Sarvey JM (1984) Blockade of long-term potentiation in rat hippocampal CA1 region by inhibitors of protein synthesis. J Neurosci $4: 3080-3088$

Stelzer A, Simon G, Kovacs G, Rai R (1994) Synaptic disinhibition during maintenance of long-term potentiation in the CA1 hippocampal subfield. Proc Natl Acad Sci USA 91:3058-3062.

Tsirka SE, Guaiandris A, Amaral DG, Strickland S (1995) Excitotoxininduced neuronal degeneration and seizure are mediated by tissue plasminogen activator. Nature 377:340-344.

Wigström H, Gustafsson B (1983) Large long-lasting potentiation in the dentate gyrus in vitro during blockade of inhibition. Brain Res 275 153-158. 